\begin{tabular}{c} 
International Journal of Engineering \& Technology, $7(3.2)(2018) 229-231$ \\
International Journal of Engineering \& Technology \\
WPC \\
Website: www.sciencepubco.com/index.php/IJET \\
Research paper \\
\hline
\end{tabular}

\title{
Compression Work of Steel Reinforced Concrete Columns
}

\author{
O. I. Lapenko ${ }^{1}$, O. V. Shevchenko ${ }^{2}$, N. N. Masud $^{3}$ \\ ${ }^{1}$ National Aviation University, Ukraine \\ ${ }^{2}$ National Aviation University, Ukraine \\ ${ }^{3}$ National Aviation University, Ukraine \\ *Corresponding Author E-Mail: My-Partner@Ukr.Net
}

\begin{abstract}
The article deals with the calculation of steel reinforced concrete columns compression and verification of local stability in fixed formwork. It is concluded that it is expedient to calculate the total stability for the resulted sections, and when checking local stability - to follow the instructions Eurocode 4. When checking the local stability of steel sheets, working as part of reinforced concrete structures, the Eurocode 4 guidelines should be followed, while taking into account the following requirements: leave out of account on the local stability of the concrete cross-section (the steel profile is completely surrounded by concrete); concrete cross-section (steel profile is completely concrete, partially concrete cross-section), the steel profile is only partially covered with concrete, as well as for other cross-sections of reinforced concrete columns provided by Eurocode 4 with the corresponding ratio $d / t$. The calculation method for the given sections in the calculation of the overall stability of compressed steel reinforced concrete elements is the simple stand one that gives satisfactory results. Calculations show that the loss of local stability of a steel sheet that works concurrently with reinforced concrete occurs at stresses greater than the force of flow in a steel sheet.
\end{abstract}

Keywords: columns; compression; critical forces; reinforced concrete structures in fixed formwork; stability.

\section{Introduction}

The calculation of the steel reinforced concrete columns with external reinforcement, the retained formwork, the problems of which are considered in [1], is essential, since the destruction of steel-reinforced concrete columns is most often associated with the loss of overall stability or their separate structural elements __ local loss of stability. Taking into account this, current normative documents for calculating steel (DBN B.2.6-198: 2014 [2]), reinforced concrete (DBN V.2.6-98: 2009 [3]), steel reinforced concrete (Eurocode 4 [4]) provide for calculations as general stability, and to check local stability.

\section{Main Body}

The theories of stability of rods and plates arose from practical construction problems, since with compressive forces, which even slightly exceed the critical load, additional bending stress reaches large quantities and directly threatens the strength of structures. Therefore, a critical condition, as a direct precondition for destruction, is considered inadmissible in real conditions of exploitation. Determination of critical loads is a responsible part of engineering design calculations and avoids loss of stability by introducing a proper stock.

As already noted, in the construction of steel reinforced concrete columns it is necessary to apply relatively thin steel sheets working as working reinforcement, so if compressed, there are problems with the loss of their local stability. The solution to this problem is complicated by the fact that these steel sheets on one, and even on both sides, are reinforced with concrete, with which they work together. Of course, these cases need to be borne in mind when calculating the local stability of reinforced concrete structures in a retained formwork.

Eurocode 4 [4] contains the general bases for calculating the complex of building constructions and complex building elements of land and engineering structures, that is, structures using steel rolled, combined with concrete.

Inspection of local stability of steel parts can not be carried out in compressed integrated racks of the following types [4]:

- concrete cross-section (steel profile is completely surrounded by concrete, Fig. 1, a);

- transverse sections filled with concrete (steel profile is completely concreted, Fig. 1, $d-f$ );

- partially concreted cross-sections (the steel profile is only partially covered with concrete, Fig. 1, $b, c$ ),

as well as for other cross-sections of steel-reinforced concrete columns (Fig. 1), if the following conditions are fulfilled:

- for steel-filled round pipes filled with concrete $d / t \leq 90 \varepsilon^{2}$;

- for rectangular steel hollow profiles $d / t \leq 52 \varepsilon$;

- for partially concreted two-tone profiles $d / t \leq 44 \varepsilon$,

where, $d$ - outer diameter of round pipes;

$h$ - is larger than the two outer dimensions, which is parallel to the main (main) axis of the cross-section;

$t$ - thickness of the wall of hollow sections filled with concrete;

$t_{l}$ and $b$-thickness and width of the shelves of the two-tailed or delivered profile. 

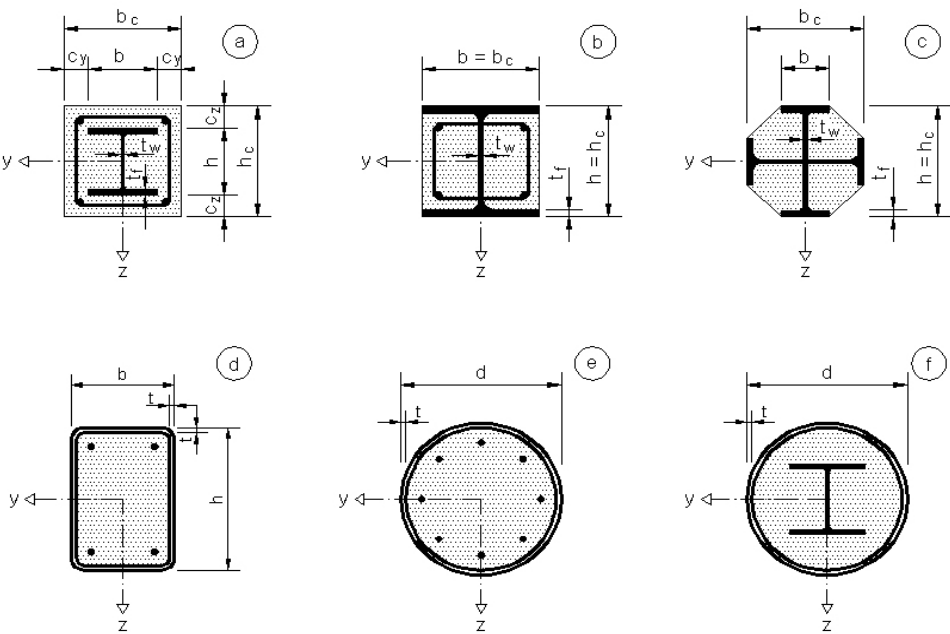

Fig. 1: Cross sections of complex racks, considered in Eurocode 4.

There are a number of structures in which sheet reinforcement is used. In the design of such structures, the task, in addition to determining the overall bearing capacity, is to consider the problem of the stability of the plate, which, on the one hand, contacts the concrete. The solution of such a problem makes it possible to determine the effort in which the steel sheet will lose stability in steel-reinforced concrete structures [5].

Consider the definition of the critical forces acting on the plate, and cause in it the initial homogeneous forces $N_{x}^{0}, N_{x y}^{0}, N_{y}^{0}$, the calculation scheme of which is shown in Fig. 2.

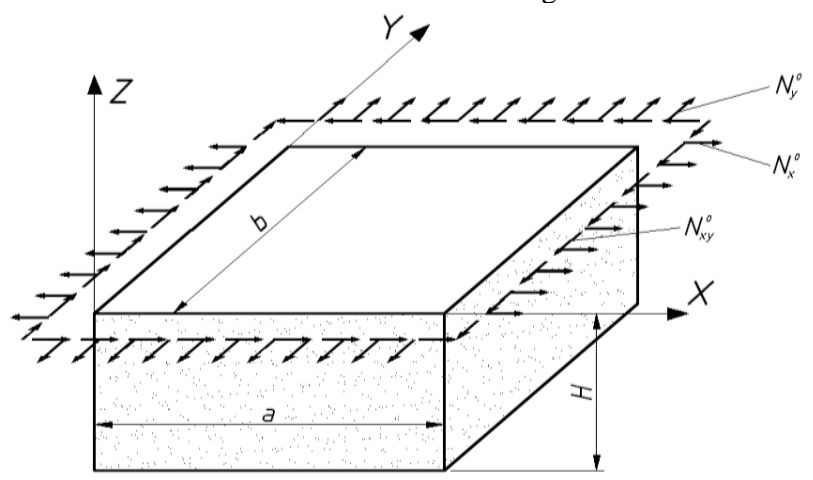

Fig. 2: Initial stress state of the plate on an elastic basis.

The equation of neutral equilibrium relative to the deflection of the plate $\omega$ is derived from the system of known linearized equations of the theory of elasticity [5]:

$$
\begin{aligned}
& K_{1} K_{2} L_{1}(\varpi)-L_{2}\left(K_{1} \varpi,_{x x}+K_{2} \varpi,_{y y}\right)+\nabla_{0}^{4} Q_{z}- \\
& -\nabla_{0}^{4}\left(N_{x}^{0} \varpi,_{x x}+2 N_{x y}^{0} \varpi,_{x y}+N_{y}^{0} \varpi,_{y y}\right)=0
\end{aligned}
$$

where, $L_{1}, L_{2}, \nabla_{0}^{4}$ - differential operators:

$$
\begin{aligned}
& L_{1}=D_{11} \frac{\partial^{4}}{\partial x^{4}}+4 D_{13} \frac{\partial^{4}}{\partial x^{3} \partial y}+2\left(C+D_{33}\right) \frac{\partial^{4}}{\partial x^{2} \partial y^{2}}+4 D_{23} \frac{\partial^{4}}{\partial x \partial y^{3}}+D_{22} \frac{\partial^{4}}{\partial y^{4}}, \\
& L_{2}=\left(D_{11} D_{33}-D_{13}^{2}\right) \frac{\partial^{4}}{\partial x^{4}}+2\left(D_{11} D_{23}-D_{12} D_{13}\right) \frac{\partial^{4}}{\partial x^{3} \partial y}+ \\
& +\left(D_{33}^{2}+2 D_{13} D_{23}+D_{11} D_{22}+C^{2}\right) \frac{\partial^{4}}{\partial x^{2} \partial y^{2}}+2\left(D_{22} D_{13}+D_{12} D_{23}\right) \frac{\partial^{4}}{\partial x \partial y^{3}}+ \\
& +\left(D_{22} D_{33}-D_{23}^{2}\right) \frac{\partial^{4}}{\partial y^{4}}
\end{aligned}
$$

$$
\begin{aligned}
& \nabla_{0}^{4}=L_{2}-\left(D_{11} K_{2}+D_{33} K_{1}\right) \frac{\partial^{2}}{\partial x^{2}}-2\left(D_{13} K_{2}+D_{23} K_{1}\right) \frac{\partial^{2}}{\partial x \partial y}- \\
& -\left(D_{33} K_{2}+D_{22} K_{1}\right) \frac{\partial^{2}}{\partial x^{2}}+K_{1} K_{2} .
\end{aligned}
$$

In this case, $D_{i j}=c_{i j} h^{3} / 12(i, j=1,2,3)$; $c_{i j}$ is a function of $E_{1}, E_{2}$, $G, v_{1}, v_{2}$.

The dependences $\varphi_{x}$ and $\varphi_{y}$ on the deflection $\omega$ are as follows:

$$
\begin{aligned}
& \nabla_{0}^{4} \varphi_{x}=D_{33} K_{1} \frac{\partial^{3} \omega}{\partial x^{3}}+\left(2 D_{23} K_{1}-D_{13} K_{2}\right) \frac{\partial^{3} \omega}{\partial x^{2} \partial y}+\left(D_{22} K_{1}-C K_{2}\right) \frac{\partial^{3} \omega}{\partial x \partial y^{2}}- \\
& -D_{23} K_{2} \frac{\partial^{3} \omega}{\partial y^{3}}-K_{1} K_{2} \frac{\partial \omega}{\partial x} \\
& \nabla_{0}^{4} \varphi_{y}=D_{33} K_{2} \frac{\partial^{3} \omega}{\partial y^{3}}+\left(2 D_{13} K_{2}-D_{23} K_{2}\right) \frac{\partial^{3} \omega}{\partial x \partial y^{2}}+\left(D_{11} K_{2}-C K_{1}\right) \frac{\partial^{3} \omega}{\partial x^{2} \partial y}- \\
& -D_{13} K_{1} \frac{\partial^{3} \omega}{\partial x^{3}}-K_{1} K_{2} \frac{\partial \omega}{\partial y}
\end{aligned}
$$

As a result of solving this problem, we obtain a equation for determining critical force:

$$
N_{c r}=\frac{D \pi^{2}}{b^{2}} K_{x}
$$

where, $D$ is cylindrical stiffness.

The parameter $K_{x}$ is determined depending on the relative stiffness of the basis.

In the study of elements without longitudinal reinforcement, the stability of the wall was considered as the stability of the plate on an elastic basis, which takes into account the joint operation of concrete and sheet fittings. Calculations show that the loss of local stability of a steel sheet that works concurrently with reinforced concrete occurs at stresses greater than the force of flow in a steel sheet. This means that the loss of local stability occures in the elastic stage, but in the elastic-plastic and plastic stage of the work of structures. The loss of stability of a steel sheet, which works together with a reinforced concrete base, occurs simultaneously with the loss of the bearing capacity of the entire structure.

Calculation of the stability of compressed columns for a steel cross section (elastic calculation) is approximate and is used for the approximate estimation of the bearing capacity of steel reinforced concrete structures. The calculation is made with the fulfillment of the conditions of stability in the plane of action of the moment and from the plane.

The calculation of the strength of the steel-cross section of steelreinforced concrete elements working on the axial compression in 
the plane of the moment of action is performed according to the equation:

$$
N / \varphi_{e} A_{\text {red }} \leq R_{y} \gamma_{c}
$$

Where, $\gamma_{c}$ - coefficient of working conditions of the design, determined in accordance with [2];

$R_{y}$ - calculated resistance of a steel element when working on tension;

$A_{\text {red }}$ - the cross-sectional area of steel reinforced concrete element is given, which is determined by the equation:

$A_{\text {red }}=A_{r}+n_{s} A_{s}+n_{b} A_{b}$

Where, $n_{s}$ and $n_{b}$ - coefficients of the cross section in accordance with the reinforcement bar and concrete to the steel I-beam section, determined from the expressions:

$$
n_{s}=\frac{E_{s}}{E_{r}}, \quad n_{b}=\frac{E_{b}}{E_{r}},
$$

where, $E_{s}, E_{b}$ та $E_{r}$ - modulus of elasticity, respectively, of rod reinforcement bars, concrete and steel I-beam section.

Flexibility of steel-reinforced concrete elements which works under axial compression is taken into account by the coefficient of longitudinal bending $\varphi_{e}$, which is determined by interpolation by (DBN B.2.6-198: 2014 [2]) with known conditional flexibility $\bar{\lambda}$ and given relative eccentricity $m_{e f}$. Conditional flexibility is determined by the equation:

$$
\bar{\lambda}=\lambda \cdot \sqrt{R_{y} / E_{r}}
$$

where, $\lambda$ is the flexibility of the steel reinforced concrete element, which is determined from the expression:

$$
\lambda=l_{\text {ef }} / i_{\text {red }}
$$

in which $i_{\text {red }}$ - the reduced radius of inertia of the entire section is calculated by the equation:

$$
i_{\text {red }}=\sqrt{I_{\text {red }} / A_{\text {red }}}
$$

in which $I_{r e d}$ - the reduced moment of inertia is determined from the expression:

$$
I_{\text {red }}=I_{r}+n_{s} I_{s}+n_{b} I_{b},
$$

where, $I_{r}, I_{s}$ and $I_{b}$ - moments of inertia constituents of the cross section of the structure.

The given relative eccentricity $m_{e f}$ is determined from the expression:

$m_{e f}=m \cdot \eta$,

where, $\eta$ - the coefficient of influence of the cross-sectional shape, which is determined according to the table (DBN B.2.6-198: 2014 [2]);

$m$ - relative eccentricity, which is determined by the equation:

$m=\frac{e_{0} A_{\text {red }}}{W_{\text {red }}}$

Where, $e_{0}$ - the full eccentricity of the application of the load $N$;
$W_{\text {red }}$ - reduced moment of resistance of the cross section of steelreinforced concrete element, which is determined by the equation:

$W_{\text {red }}=\frac{I_{\text {red }}}{y_{\max }}$

where, $y_{\max }$ - the distance from the center of gravity of the section to the most remote point of the section along the $\mathrm{Y}$ axis.

\section{Conclusion}

The considered method successfully can be used for the calculation of compressed flexible steel reinforced concrete columns.

Thus, when checking the local stability of steel sheets that work as part of reinforced concrete structures, the Eurocode 4 [4] guidelines should be followed, while taking into account the following requirements: do not count on the local stability of the concrete cross section (the steel profile is completely surrounded by concrete); concrete cross-section (steel profile is completely concrete, partially concrete crosssection), the steel profile is only partially covered with concrete, as well as for other cross sections of reinforced concrete columns provided by Eurocode 4 with the corresponding ratio $d / t$. In calculating the overall stability of compressed steel reinforced concrete elements, the simplest and the most satisfactory results is the method of calculation for the given sections. This method is quite simple and allows to take into account tabular factors of the consideration of flexibility, contained in the current DBN B.2.6-198: 2014 [2].

\section{References}

[1] Storozhenko L.I., Lapenko O.I. (2008), Zalizobetonni konstruktsii v neznimnii opalubtsi, Poltava: ASMI, pp. 210-268

[2] DBN V.2.6-198:2014. Stalevi konstruktsii. Normy proektuvannia. K.: Minrehionbud Ukrainy, 2014. -122 p.

[3] DBN V.2.6-98:2009 . Betonni ta zalizobetonni konstruktsii. - K.: Minrehionbud Ukrainy, 2011. - 71 p.

[4] Eurocode 4. Common Unified Rules for Composite Steel and concrete Structures European Committee for Standardization. (CEN) ENV. $1994-1-1: 1992 .-180$ p.

[5] Ilhamov M.A., Ivanov V.A., Hulin B.V. (1987), Raschet obolochek s upruhim zapolnitelem, M.: Nauka, pp. 85-136.

[6] Storozhenko, L., Butsky, V., Taranovsky, O. Stability of Compressed Steel Concrete Composite Tubular Columns with Centrifuged Cores // Journal of constructional steel research; 46, 1/3; 484; Second World Conference on Steel in Construction ; 1998

[7] Piskunov, V.G., Gorik, A.. \& Cherednikov, V.N. Mechanics of $\begin{array}{llll}\text { Composite } & \text { Materials } & \text { (2000) } & \end{array}$ https://doi.org/10.1023/A:1006798314569

[8] Kochkarev D. Calculation methodology of reinforced concrete elements based on estimated resistance of reinforced concrete / D. Kochkarev, T. Galinska // Matec Web of Conferences 116, 02020 (2017), Materials science, engineering and chemistry, Transbud-2017, Kharkiv, Ukraine, April 19-21, 2017. https://doi.org/10.1051/matecconf/201711602020 